\title{
A comparison study of metabolic profiles, immunity, and brain gray matter volumes between patients with bipolar disorder and depressive disorder
}

Ya-Mei Bai ${ }^{1,2,3}$, Mu-Hong Chen 1,2,3, Ju-Wei Hsu ${ }^{1,2}$, Kai-Lin Huang ${ }^{1,2}$, Pei-Chi Tu 1,2,4,5, Wan-Chen Chang 1,4, Tung-Ping Su', Cheng Ta Li ${ }^{1,2,3}$, Wei-Chen Lin ${ }^{1,2,3}$ and Shih-Jen Tsai ${ }^{1,2,3^{*}}$

\begin{abstract}
Background: Previous individual studies have shown the differences in inflammatory cytokines and gray matter volumes between bipolar disorder (BD) and unipolar depression (UD). However, few studies have investigated the association between pro-inflammatory cytokines and differences in brain gray matter volumes between BD and UD.

Methods: In this study, 72 BD patients and 64 UD patients were enrolled, with comparable gender and age distributions (33.8\% males and an average age of $39.3 \pm 13.7$ years). Each participant underwent metabolic profiling (including body mass index (BMI), glucose, triglyceride, high-density lipoprotein (HDL), leptin, insulin, adiponectin), pro-inflammatory cytokine (including soluble interleukin-6 receptor (sIL-6R), soluble interleukin-2 receptor (sIL-2R), Creactive protein (CRP), soluble tumor necrosis factor receptor type 1 (STNF-R1) examinations, and structural magnetic resonance imaging exams. Voxel-based morphometry was performed to investigate the gray matter volume differences between BD and UD patients. Correlations between pro-inflammatory cytokines and the gray matter volume difference were analyzed.
\end{abstract}

Results: Compared to UD patients, the BD group had significantly higher BMI, and higher levels of sIL-6R and sTNFR1 than the UD patients. The BMI significantly correlated with the level of pro-inflammatory cytokines. Adjusted for age, sex, BMI, duration of illness and total intracranial volume, the BD individuals had significantly more reduced gray matter volumes over 12 areas: R. cerebellar lobule VIII, R. putamen, L. putamen, R. superior frontal gyrus, L. lingual gyrus, L. precentral gyrus, R. fusiform gyrus, L. calcarine, R. precuneus, L. inferior temporal gyrus, L. hippocampus, and L. superior frontal gyrus. These 12 gray matter volume differences between BP and UD patients negatively correlated with sIL-6R and sTNF-R1 levels.

Conclusions: Our results suggested that BD patients had higher BMI and pro-inflammatory cytokine levels in comparison to UD patients, especially IL-6 and sTNF-R1, which may contribute to greater gray matter reductions in BD patients in comparison to UD patients. The results support the neuro-inflammation pathophysiology mechanism in mood disorder. It is clinically important to monitor BMI, which, in this investigation, positively correlated with levels of inflammatory cytokines.

Keywords: Bipolar disorder, Major depressive disorder, Pro-inflammatory cytokine, Magnetic resonance imaging, Gray matter, Voxel-based morphometry

\footnotetext{
*Correspondence: tsai610913@gmail.com

'Department of Psychiatry, Taipei Veterans General Hospital, No. 201, Shih-Pai

Road, Sec. 2, 11217 Taipei, Taiwan

Division of Psychiatry, Faculty of Medicine, National Yang-Ming University,

Taipei, Taiwan

Full list of author information is available at the end of the article
}

(c) The Author(s). 2020 Open Access This article is distributed under the terms of the Creative Commons Attribution 4.0 International License (http://creativecommons.org/licenses/by/4.0/), which permits unrestricted use, distribution, and reproduction in any medium, provided you give appropriate credit to the original author(s) and the source, provide a link to the Creative Commons license, and indicate if changes were made. The Creative Commons Public Domain Dedication waiver (http://creativecommons.org/publicdomain/zero/1.0/) applies to the data made available in this article, unless otherwise stated. 


\section{Background}

Accumulating evidence suggests that inflammatory processes play an important role in the pathogenesis, phenomenology, comorbidity, and treatment of mood disorders $[1,2]$. A bidirectional circuit between the immune and neuroendocrine systems has been suggested as enabling a complex reciprocal relationship between the immune and hypothalamic-pituitary-adrenal (HPA) axis functions in unipolar depression (UD) [3]. Patients with depression show elevated peripheral inflammatory biomarkers, even in the absence of medical illness [4-6]. Patients treated with cytokines are at a greater risk of developing a depressive disorder, and the administration of anti-cytokines to patients with concurrent depression and inflammatory disease has resulted in relief of depressive symptoms [1, 7-10]. Increased expressions of inflammatory mediators in depressed patients may lead to a poor response to antidepressant drug therapy [1], affecting brain signaling patterns, cognition, and the production of a constellation of symptoms, termed "sickness behavior" [11, 12]. Regarding bipolar disorder (BD), available evidence indicates that $\mathrm{BD}$ and inflammation are linked through shared genetic polymorphisms and gene expressions [13], and multi-system inflammatory involvement may be present during the early stage of $\mathrm{BD}$ [14]. Pro-inflammatory cytokines have unique and specific actions on neurons and circuits within the central nervous system, influencing the microglial activation [15], signaling molecules in neurotransmission, memory, and glucocorticoid function, as well as activity control [16]. Inflammatory mediators may alter monoamine and glutamate neurotransmissions, glucocorticoid receptor resistance, and hippocampal neurogenesis [17].

Previous imaging studies have demonstrated that brain gray matter $(\mathrm{GM})$ volume reductions in several specific regions, such as in the prefrontal cortex, occur in both $\mathrm{BD}$ and UD patients, and are associated with disease severity and cognitive impairment [18-21]. However, few studies have directly compared metabolic profiles, the pro-inflammatory cytokine and associated brain GM volume changes between $\mathrm{BD}$ and UD individuals. In general, $\mathrm{BD}$ is regarded as a more severe mood disorder than UD with earlier onset, more recurrent episodes, more deficits in neurocognitive function [22-25], and more pathology in neuroimaging findings with more widespread volumetric changes [26-29]. Direct comparisons of brain GM changes revealed that, compared with UD patients, BD individuals showed reduced GM volumes in the right inferior frontal gyrus, middle cingulate gyrus, hippocampus, and amygdala; indicating that $\mathrm{BD}$ patients exhibited a more pervasive GM volume reduction than UD patients $[30,31]$. However, the mechanisms underlying the GM volume differences between BD and UD remain unknown. Our previous study found the pro-inflammatory cytokines levels of soluble interleukin-6 receptor (sIL-6R), soluble interleukin-2 receptor (sIL-2R), C-reactive protein (CRP), and soluble tumor necrosis factor receptor type 1 (sTNF-R1) were significantly higher in BD patients than in UD patients, indicating more severe inflammatory dysregulations in $\mathrm{BD}$ than UD [32]. Whether the GM volume reduction differences are related to a more severe inflammatory dysregulation in BD patients than UD individuals have rarely been investigated. In this study, we investigated the association between pro-inflammatory cytokines and differences in brain gray matter volumes between BD and UD. The results may contribute to the understanding of the role of inflammation dysregulation in mood disorders.

\section{Methods \\ Participants}

Patients aged between 20 and 65 years who met the Diagnostic and Statistical Manual of Mental Disorders, Fourth Edition, Text Revision (DSM-IV-TR) criteria for bipolar disorder or unipolar depression with a Clinical Global Impression-Severity (CGI-S) scale for bipolar disorder or unipolar depression $\leq 3$ were included in the current study. The exclusion criteria included any DSMIV diagnosis of the following: lifetime history of schizophrenia or any other psychosis, intellectual disability, organic mental disorder, autoimmune/immune diseases, substance abuse in the past 3 months or dependence in the past 6 months, pregnancy or breastfeeding, and unstable physical illnesses. The study was approved by the Institutional Review Board of the Taipei Veterans General Hospital and conducted in accordance with the Declaration of Helsinki. Written informed consent was obtained from all patients prior to their inclusions in the study.

\section{Measurements of metabolic profiles and pro- inflammatory cytokines}

The metabolic profiles, including body mass index (BMI), glucose, triglyceride (TG), high-density lipoprotein (HDL), leptin, ghrelin, insulin, adiponectin, were examined. Serum glucose, triglyceride, and cholesterol levels were measured using a glucose oxidase autoanalyzer, a triglyceride enzyme autoanalyzer, and a cholesterol oxidase autoanalyzer, respectively (Dimension RxL, DADE Behring Company, Inc., Newark, DE, USA); ghrelin was measured using a radioimmunoassay (RIA) kit (Peninsula Laboratories, Inc., San Carlos, CA, USA). Insulin concentrations were analyzed using a radioimmunoassay kit (Coat-A Count Insulin; Diagnostic Product Corporation, Los Angeles, CA, USA). Serum adiponectin level was measured using a quantitative Human Adiponectin ELISA Kit (B-Bridge International, Inc., Mountain View, CA, USA). 
The pro-inflammatory cytokine levels, including sIL-6R, sIL-2R, CRP, and sTNF-R1, were determined using enzyme-linked immunosorbent assay (ELISA) kits (R\&D Systems, Minneapolis, MN, USA). Fasting serum samples were collected in serum separator tubes, clotted for 30 min, and stored at $-80^{\circ} \mathrm{C}$ until use. All assays were performed according to the vendor's instructions. The final absorbance of each sample of the mixture was measured and analyzed at $450 \mathrm{~nm}$ using an ELISA plate reader with Bio-Tek Power Wave Xs and Bio-Tek's KC junior software (Winooski, VT, USA). The standard range was considered as specified in the vendor's instructions. A linear regression $R^{2}$ value of at least 0.95 was considered a reliable standard curve.

\section{Magnetic resonance imaging acquisition}

All brain images were acquired on a 3.0-T GE Discovery MR750 whole-body high-speed MRI device. Automated shimming procedures were performed, and scout images were obtained. A high-resolution structural image was acquired in the axial plane using the FSPGR sequence (BRAVO) on GE equipment with parameters (repetition time $[\mathrm{TR}]=12.23 \mathrm{~ms}$, echo time $[\mathrm{TE}]=5.18 \mathrm{~ms}$, inversion time $[\mathrm{TI}]=450 \mathrm{~ms}$, and flip angle $=12^{\circ}$ ) and an isotropic 1 -mm voxel (FOV $256 \times 256$ ). One hundred sixty-eight contiguous horizontal $1 \mathrm{~mm}$ thick slices were acquired parallel to the anterior commissure-posterior commissure line. These slices covered the cerebellum of each participant. To minimize the generation of motion artifacts during image acquisition, each participant's head was immobilized with cushions inside the coil.

\section{Voxel-based morphometry}

Individual high-resolution T1-weighted volumetric images were processed using Statistical Parametric Mapping (SPM12, Wellcome Institute of Neurology, University College London, UK) executed in Linuxbased MATLAB 2014a (MathWorks, Natick, MA, USA) with default settings. In the current study, the detailed VBM approach included the following: Data were first carefully checked by an experienced radiologist to rule out any scanner artifacts, motion problems, or gross anatomical abnormalities for each participant. After data checking and origin identification, the Segment Toolbox from SPM12 was applied to every T1-weighted MR image to extract tissue maps corresponding to gray and white matters, and cerebrospinal fluid in native space. To achieve higher accuracy of registration across subjects, all native space tissue segments were imported into a rigidly aligned space and iteratively registered to group-specific templates that were generated from all structural images in this study through nonlinear warping using the DARTEL toolbox. These images were resampled to $1.5 \mathrm{~mm}$ isotropic voxels. Subsequently, the resliced images of gray and white matters were registered to a subject-specific template using the DARTEL template-creation toolbox to improve inter-subject alignment, and the normalization function of the toolbox was used to normalize the individual images of gray and white matters to MNI space ( $1.5 \mathrm{~mm}$ isotropic voxel). Finally, the gray matter map of each subject was warped using their corresponding, smooth, and reversible deformation parameters to the custom template space and then to the MNI standard space. For the GM volume, the warped images of gray matter were modulated by calculating the Jacobian determinants derived from the special normalization step and by multiplying each voxel by the relative change in volume. The modulation step was performed to correct volume changes that might have occurred during nonlinear normalization. The warped modulated images of gray matter were smoothened through the convolution of an 8-mm full-width, at half-maximum isotropic Gaussian kernel before tissue volume calculation and voxel-wise group comparisons. The total intracranial volume (TIV) was determined as the sum of GM, WM, and CSF volumes [33, 34].

\section{Statistical analysis}

To assess differences in demographic and clinical data, we used one-way analysis of variance for continuous variables and Fisher's chi-squared test for nominal variables. $P<0.05$ was used to indicate statistical significance. For imaging data, voxel-wise GM volume differences between the two disease groups were investigated using analysis of covariance (ANCOVA) with co-varying the age, sex, BMI, duration of illness, and TIV. To avoid possible edge effects around the margin between different tissue types, all voxels with a GM probability value $<0.2$ (absolute threshold; range, $0-1$ ) were excluded. The threshold was set at $P<0.05$ (corrected for familywise error rate (FEW) at the cluster level with a voxelwise $P<0.001$ using a combined height and extent threshold technique based on 10,000 Monte-Carlo simulations calculated through the Analysis of Functional NeuroImages (AFNI) program, 3dClustSim (the successor of AlphaSim; Cox, 1996; http://afni.nimh.nih.gov/ pub/dist/doc/program_help/3dClustSim.html). In this study, the statistical threshold for each voxel was set at PFWE-corrected $<0.05$, with a cluster size of at least 104 voxels as the threshold, based on the results of the Monte Carlo simulation. The results (Puncorrected < 0.001 and $\mathrm{kE}>104$ ) were considered statistically significant. The regional GM volumes were extracted from the significant clusters of group comparison for each participant. We analyzed the correlation between GM volume differences between the two groups and proinflammatory cytokine levels. 


\section{Results}

The demographic data of the study participants are presented in Table 1 . In total, 72 patients with BD and 64 patients with UD were enrolled $(33.8 \%$ males and an average age of $39.3 \pm 13.7$ years), with comparable gender and age distributions. The BD group had significantly higher BMI values, higher levels of sIL-6R and sTNF-R1 than the UD patients (Table 1 , all $P<0.05$ ). There were no significant differences in the rate of metabolic syndrome between BD and UD patients. The BMI correlated significantly with HDL $(r=-0.303, P<0.01)$, leptin $(r=0.600, P<0.01)$, insulin $(r=0.482, P<0.01)$, adiponectin $(r=-0.311, P<0.01)$, sIL-6R $(r=0.326, P<0.01)$, sIL-2R $(r=0.250, P<0.01)$, CRP $(r=0.325, P<0.01)$, and sTNF-R1 $(r=0.544, P<0.01)$ levels.

Among the 64 patients with UD, there were 19 (29.7\%) patients with selective serotonin reuptake inhibitors (SSRIs), 18 (28.1\%) patients with serotoninnorepinephrine reuptake inhibitors (SNRIs), 11 (17.2\%) patients with norepinephrine dopamine reuptake inhibitors (NDRIs), $4(6.3 \%)$ patients with noradrenergic and specific serotonergic antidepressants (NaSSAs), and 12 (18.7\%) with agomelatine. Among the 72 patients with BD, $11(15.3 \%)$ patients were treated with lithium or valproic acid only, 18 (25\%) patients were treated with atypical antipsychotics only, $36(50 \%)$ patients were treated with lithium or valproic acid plus atypical antipsychotics, and 7 (9.7\%) patients were treated with other medications including lamotrigine and carbamazepine. To investigate the influence of medications on cytokine levels, ANOVA tests were performed, and no significant differences in any of the cytokines were noted among patients taking different groups of medications in the BD or UD group (Tables 2 and 3).

For the comparison of gray matter, none of the brain regions were larger in patients with bipolar disorder than they were in patients with unipolar depression. BD patients had significantly reduced gray matter volume over 12 areas: R. cerebellar lobule VIII, R. putamen, L. putamen, R. superior frontal gyrus, L. lingual gyrus, L. precentral gyrus, R. fusiform gyrus, L. calcarine, R. precuneus, L. inferior temporal gyrus, L. hippocampus, L. superior frontal gyrus, adjusted for age, sex, BMI, duration of illness, and TIV (Table 4, Fig. 1). These 12 gray matter volume differences between $\mathrm{BP}$ and UD negatively correlated with sIL-6R, sTNF-R1 levels (Table 5).

\section{Discussion}

In this study, we found that BD patients had significantly higher levels of sIL-6R, sTNF-R1 levels than the UD patients. Our first study with different sample of 109 patients with UD, has found that the level of proinflammatory cytokines correlated with the severity of depressive symptoms [35]. Then, we enrolled other 130 $\mathrm{BD}$ patients, and 149 UD patients, we found the BD patients had significantly higher levels of cytokines than

Table 1 Demographic data, metabolic profiles, and levels of pro-inflammatory cytokines between patients with bipolar disorder and unipolar depression

\begin{tabular}{llll}
\hline & Bipolar disorder $(n=72)$ & Unipolar depression $(n=64)$ & $P$ value \\
\hline Demographic data & & & $19 / 45$ \\
Sex (M/F, $n)$ & $27 / 45$ & $39.0(15.3)$ & 0.336 \\
Age (SD) & $39.5(12.3)$ & & 0.837 \\
Metabolic profiles & & $23.7(4.03)$ & $0.002^{*}$ \\
BMI (SD) & $26.6(5.2)$ & $89.1(9.2)$ & 0.758 \\
Glucose (SD) & $89.8(16.4)$ & $107.4(69.9)$ & 0.400 \\
Triglyceride (SD) & $119.5(93.5)$ & $56.8(13.4)$ & 0.876 \\
High density lipoprotein (HDL) & $56.4(16.9)$ & $9013.4(7372.7)$ & 0.159 \\
Leptin (SD) & $11,431.2(10,944.5)$ & $8.12(14.04)$ & 0.551 \\
Insulin (SD) & $9.65(14.78)$ & $7505.1(5664.9)$ & 0.141 \\
Adiponectin (SD) & $6158.4(4670.2)$ & $22.6 \%$ & 0.527 \\
Metabolic syndrome (\%) & $23.6 \%$ & & $<0.001^{* *}$ \\
Inflammation index (pg/ml) & & $29,420.91(8282.58)$ & 0.135 \\
SIL-6R (SD) & $36,917.86(11,001.38)$ & $671.83(246.70)$ & 0.840 \\
SIL-2R (SD) & $747.39(323.22)$ & $1823.09(2289.56)$ & $<0.001^{* *}$ \\
CRP (SD) & $1751.60(1929.26)$ & $748.46(161.44)$ & \\
STNFR1 (SD) & $1216.55(468.646)$ &
\end{tabular}

BMI body mass index, SD standard deviation, MARDS Montgomery-Åsberg Depression Rating Scale, YAMRS The Young Mania Rating Scale; Global Assessment of Function Scale, sIL-2R soluble IL-2 receptor, sIL-6R soluble IL-6 receptor, CRP C-reactive protein, sTNFR1 soluble tumor necrosis factor-a receptor-1 ${ }^{*} P<0.05,{ }^{* *} P<0.001$ 
Table 2 Comparison of cytokines among patients with unipolar depression taking different types of antidepressant

\begin{tabular}{|c|c|c|c|c|c|c|}
\hline & $\begin{array}{l}\text { SSRI } \\
(n=19)\end{array}$ & $\begin{array}{l}\text { SNRI } \\
(n=18)\end{array}$ & $\begin{array}{l}\text { NDRI } \\
(n=11)\end{array}$ & $\begin{array}{l}\text { NaSSA } \\
(n=4)\end{array}$ & $\begin{array}{l}\text { Agomelatine } \\
(n=9)\end{array}$ & Significance \\
\hline C-reactive protein (CRP) $(\mathrm{pg} / \mathrm{ml})$ & $2322.6 \pm 3028.6$ & $999.8 \pm 1408.8$ & $3133.2 \pm 2206.4$ & $978.3 \pm 605.4$ & $1366.4 \pm 1930.0$ & n.s. \\
\hline $\begin{array}{l}\text { Soluble interleukin-2 receptor } \\
\text { (slL-2R) }(\mathrm{pg} / \mathrm{ml})\end{array}$ & $643.7 \pm 211.2$ & $611.5 \pm 177.7$ & $851.0 \pm 358.3$ & $825.1 \pm 316.8$ & $561.7 \pm 220.8$ & n.s. \\
\hline $\begin{array}{l}\text { Soluble interleukin-6 receptor } \\
\text { (slL-6R) }(\mathrm{pg} / \mathrm{ml})\end{array}$ & $29,504.2 \pm 5970.7$ & $28,075.4 \pm 9047.5$ & $29,518.2 \pm 9497.3$ & $35,502.9 \pm 8097.8$ & $28,205.8 \pm 11,328.8$ & n.s. \\
\hline $\begin{array}{l}\text { Soluble tumor necrosis factor } \\
\text { receptor type } 1 \text { (sTNF-R1) (pg/ml) }\end{array}$ & $774.7 \pm 134.7$ & $753.1 \pm 147.2$ & $779.0 \pm 235.0$ & $863.9 \pm 583.3$ & $653.0 \pm 181.7$ & n.s. \\
\hline
\end{tabular}

NaSSA noradrenergic and specific serotonergic antidepressant, $N D R I$ norepinephrine dopamine reuptake inhibitor, SNRI serotonin-norepinephrine reuptake inhibitor, SSRI selective serotonin reuptake inhibitor, n.s. not significant

UD patients [30]. Among the $130 \mathrm{BD}$ patients, we further found the patients with bipolar I disorder had significantly higher levels of sTNF-R1 than the patients with bipolar II disorder; the patients in manic/hypomanic states had significantly higher levels of sTNFR1than the patients in a depressive state [36]. Combined with our previous $[30,35,36]$ and the present studies with different samples, our series reports supported the pro-inflammatory cytokines may be a potential biomarker for mood disorders, and BD patients had higher immune dysregulations than UD patients.

In this study, we further investigated the association between brain pro-inflammatory cytokines and GM volume changes between BD and UD patients. We found that the BD group had significantly reduced GM volumes over 12 areas: R. cerebellar lobule VIII, R. putamen, L. putamen, R. superior frontal gyrus, L. lingual gyrus, L. precentral gyrus, R. fusiform gyrus, L. calcarine, R. precuneus, L. inferior temporal gyrus, L. hippocampus, L. superior frontal gyrus, adjusted for age, sex, BMI, duration of illness, and total intracranial volume. Furthermore, these 12 GM volume differences between BP and UD patients negatively correlated with sIL-6R, sTNF-R1 levels. These results supported our study hypothesis that BD patients have higher levels of proinflammatory cytokines, which associated with greater widespread GM volume changes. The meta-analysis suggested that MDD and BD are characterized by common patterns of gray-matter volume changes [37]. Our results may offer evidence that cytokine can be a biomarker for gray-matter volume change in mood disorders. As far as the differences in brain volumes preferentially in the left or right sides for some areas in our study, we did not check the patients preferentially handed. Ocklenburg et al. indicated that the structural brain correlates of handedness are unlikely to be rooted in macroscopic gray matter area differences that can be assessed with VBM [38]. In fact, most clinical imaging studies showed different left or right side brain areas in results. Few studies can have consistent bilateral symmetrical findings. These may be related to sample size and interindividual lateralization differences.

Our results showed that IL-6, sTNF-R1 in particular may contribute to greater GM reductions in bipolar disorder in comparison to UD patients. There were some studies which supported our findings. sIL-6R has been consistently observed to be higher in patients with BD [32, 36, 39, 40]. Another study also showed sIL-6 R level reflecting the illness activity in bipolar disorder [41]. In a 13-year longitudinal study, higher levels of systemic inflammatory marker IL-6 in childhood were associated with hypomanic symptoms in young adulthood [42]. Higher sIL-6R levels were also associated with lower functional connectivity between the medial prefrontal cortex (mPFC) and subcortical structures involved in emotional processing in BD patients [43]. In patients with UD, increased IL-6 levels were associated with decreased performance on simple and choice

Table 3 Comparison of cytokines in patients with bipolar disorder taking a different type of treatment

\begin{tabular}{|c|c|c|c|c|c|}
\hline & $\begin{array}{l}\text { Li or VPA only } \\
(n=11)\end{array}$ & $\begin{array}{l}\text { AA only } \\
(n=18)\end{array}$ & $\begin{array}{l}\text { Li or VPA plus AA } \\
(n=36)\end{array}$ & $\begin{array}{l}\text { Lamotrigine or carbamazepine } \\
(n=7)\end{array}$ & Significance \\
\hline C-reactive protein (CRP) $(\mathrm{pg} / \mathrm{ml})$ & $1725.3 \pm 1053.7$ & $1888.2 \pm 2337.9$ & $1701.7 \pm 1449.0$ & $1088.2 \pm 1085.4$ & n.s. \\
\hline $\begin{array}{l}\text { Soluble interleukin-2 receptor } \\
\text { (sIL-2R) (pg/ml) }\end{array}$ & $692.3 \pm 266.6$ & $797.9 \pm 337.5$ & $760.2 \pm 352.2$ & $630.5 \pm 250.1$ & n.s. \\
\hline $\begin{array}{l}\text { Soluble interleukin-6 receptor } \\
\text { (slL-6R) (pg/ml) }\end{array}$ & $37,253.7 \pm 6243.3$ & $36,311.6 \pm 10,217.6$ & $38,994.4 \pm 12,634.2$ & $29,989.6 \pm 8728.0$ & n.s. \\
\hline $\begin{array}{l}\text { Soluble tumor necrosis factor } \\
\text { receptor type } 1 \text { (sTNF-R1) (pg/ml) }\end{array}$ & $1203.3 \pm 311.3$ & $1050.6 \pm 319.1$ & $1319.2 \pm 577.5$ & $1158.1 \pm 200.1$ & n.s. \\
\hline
\end{tabular}


Table 4 Gray matter volume differences between bipolar disorder (BD) and unipolar depression (UD) ${ }^{a}$

\begin{tabular}{|c|c|c|c|c|c|c|c|}
\hline Index & Harvard-Oxford Cortical Structural Atlas & $x$ & $y$ & $z$ & Cluster size & $T$ value & $\begin{array}{l}P \text { value } \\
\text { (FDR corr.) }\end{array}$ \\
\hline \multicolumn{8}{|c|}{$\mathrm{BD}>\mathrm{UD}$} \\
\hline & & - & - & - & - & - & - \\
\hline \multicolumn{8}{|c|}{$\mathrm{UD}>\mathrm{BD}$} \\
\hline 1 & R. cerebellar lobule VIII & 20 & -58 & -50 & 15,271 & 8.15 & $<0.001^{* *}$ \\
\hline 2 & R. putamen & 29 & -3 & -2 & 3835 & 5.92 & $<0.001^{* *}$ \\
\hline 3 & L. putamen & -26 & -3 & -1 & 3437 & 5.82 & $<0.001^{* *}$ \\
\hline 4 & R. superior frontal gyrus & 25 & 53 & -5 & 801 & 4.43 & $0.001^{*}$ \\
\hline 5 & Left lingual gyrus & -27 & -91 & -13 & 679 & 4.34 & $0.001^{*}$ \\
\hline 6 & L. precentral gyrus & -48 & 6 & 29 & 543 & 4.26 & $0.001^{*}$ \\
\hline 7 & R. fusiform gyrus & 32 & -48 & -6 & 290 & 4.25 & $0.001^{*}$ \\
\hline 8 & L. calcarine & -13 & -77 & 7 & 216 & 4.19 & $0.001^{*}$ \\
\hline 9 & R. precuneus & 1 & -63 & 53 & 258 & 4.19 & $0.001^{*}$ \\
\hline 10 & L. inferior temporal gyrus & -44 & -14 & -31 & 355 & 4.13 & $0.001^{*}$ \\
\hline 11 & L. hippocampus & -25 & -14 & -23 & 143 & 4.09 & $0.001^{*}$ \\
\hline 12 & L. superior frontal gyrus & -17 & 56 & -12 & 238 & 3.93 & $0.002^{*}$ \\
\hline
\end{tabular}

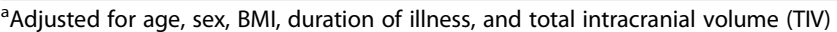

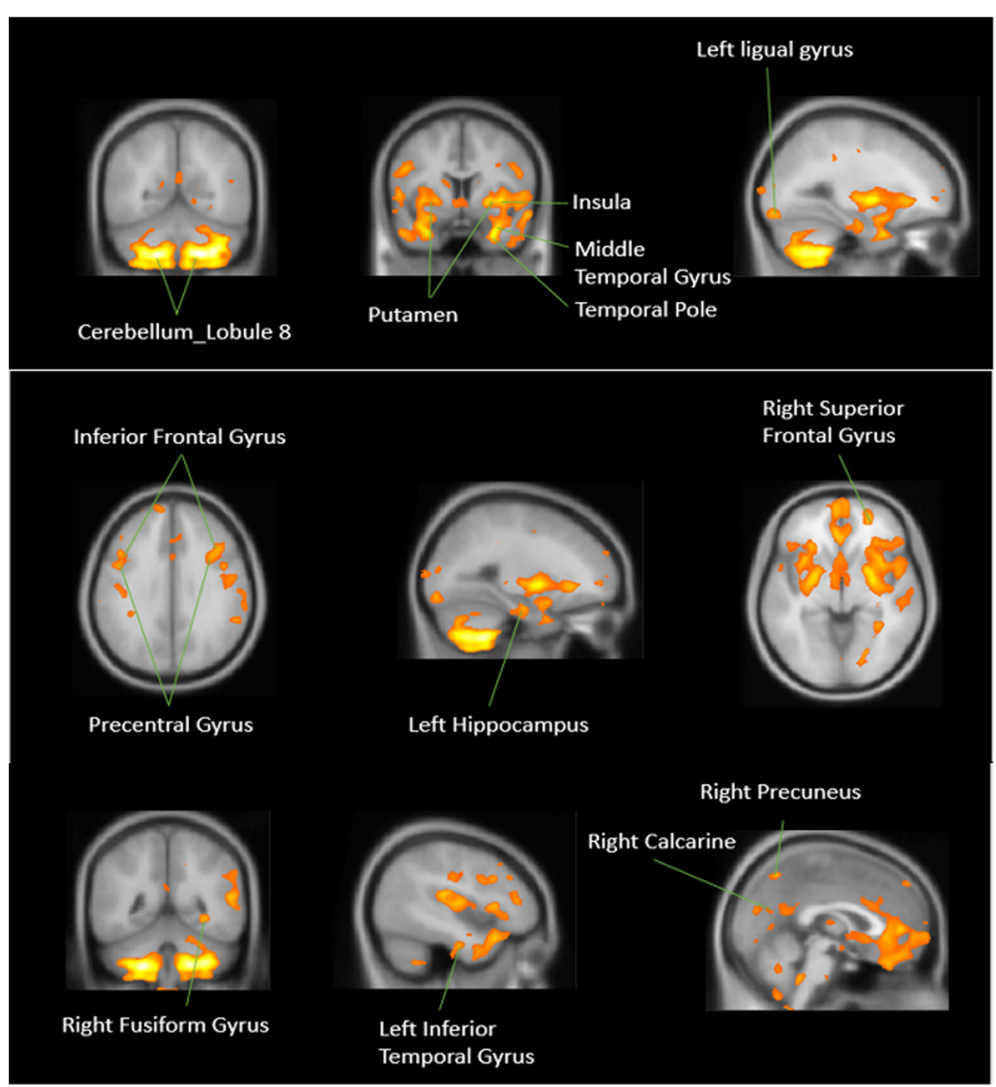

Fig. 1 Gray matter volume differences between bipolar disorder (BD) and unipolar depression (UD) (UD > BD) $)^{a}$. a Adjusted for age, sex, BMI, duration of illness, and total intracranial volume (TIV) 
Table $\mathbf{5}$ Correlation between gray matter volume reduction and levels of pro-inflammatory cytokines

\begin{tabular}{|c|c|c|c|c|c|c|c|c|c|c|c|c|}
\hline Region & $\begin{array}{l}\text { R. } \\
\text { cerebellar } \\
\text { lobule VIII }\end{array}$ & $\begin{array}{l}\text { R. } \\
\text { putamen }\end{array}$ & $\begin{array}{l}\mathrm{L} \text {. } \\
\text { putamen }\end{array}$ & $\begin{array}{l}\text { R. superior } \\
\text { frontal } \\
\text { gyrus }\end{array}$ & $\begin{array}{l}\text { L. } \\
\text { lingual } \\
\text { gyrus }\end{array}$ & $\begin{array}{l}\text { L. } \\
\text { precentral } \\
\text { gyrus }\end{array}$ & $\begin{array}{l}\text { R. } \\
\text { fusiform } \\
\text { gyrus }\end{array}$ & $\begin{array}{l}\text { L. } \\
\text { calcarine }\end{array}$ & $\begin{array}{l}\mathrm{R} \text {. } \\
\text { precuneus }\end{array}$ & $\begin{array}{l}\text { L. inferior } \\
\text { temporal } \\
\text { gyrus }\end{array}$ & $\begin{array}{l}\text { L. } \\
\text { hippocampus }\end{array}$ & $\begin{array}{l}\text { L. superior } \\
\text { frontal } \\
\text { gyrus }\end{array}$ \\
\hline sTNFR1 & $-0.324^{* *}$ & $-0.352^{* *}$ & $-0.360^{* *}$ & $-0.217^{*}$ & $-0.196^{*}$ & $-0.289^{* *}$ & $-0.335^{* *}$ & $-0.289^{* *}$ & $-0.195^{*}$ & $-0.423^{* *}$ & -0.168 & -0.138 \\
\hline SIL-6R & $-0.173^{* *}$ & $-0.321^{* *}$ & $-0.355^{* *}$ & $-0.254^{* *}$ & $-0.181^{*}$ & $-0.284^{* *}$ & $-0.188^{*}$ & $-0.212^{*}$ & $-0.176^{*}$ & $-0.232^{* *}$ & -0.099 & $-0.194^{* *}$ \\
\hline SIL-2R & -0.048 & -0.109 & -0.103 & -0.028 & -0.013 & -0.098 & -0.104 & -0.120 & -0.047 & -0.121 & 0.007 & 0.003 \\
\hline CRP & 0.007 & -0.054 & -0.033 & -0.058 & -0.010 & -0.006 & 0.019 & -0.038 & 0.117 & -0.085 & -0.110 & 0.007 \\
\hline
\end{tabular}

$R$ right, $L$ left, sIL-2R soluble IL-2 receptor, sIL-6R soluble IL-6 receptor, CRP C-reactive protein, sTNFR1 soluble tumor necrosis factor-a receptor-1 Italicized data indicate the statistical significance

${ }^{* *} p<0.01,{ }^{*} p<0.05$

movement time tasks [44]. For healthy subjects, previous studies also demonstrated an association between subgenual cingulate activity and mesolimbic connectivity with elevated IL-6 [45]. Among 1841 participants aged 65 to 80 community-dwelling elderly free of dementia, higher IL-6 levels were associated with lower gray matter and hippocampal volumes, and increased CSF volumes in a dose-relationship pattern [46]. Other studies also showed that IL-6 was associated with decreased total brain volume [47], hippocampal gray matter volume $[48,49]$, cortical atrophy [50], increased white matter hyperintensities [44], and also the rate of cortical thinning during the aging process [51]. The higher mean IL-6 concentrations were associated with accelerated annual rates of cortical thinning in the inferior temporal poles, transverse frontopolar gyri within the left hemisphere, and subcentral gyrus and sulcus within the right hemisphere [52]. Regarding sTNF-R1, a higher level of sTNF-R1 is associated with general disease severity, psychotic features and deteriorated function among patients with bipolar disorder and schizophrenic patients [52]. TNF-alpha activates an apoptotic signaling cascade leading to apoptosis and cell death, and also acts through other signaling networks impacting neuronal development, synaptic transmission, and cell survival [53]. TNF-alpha is also associated with endothelial leakage and endothelial cell activation [54], neurotoxicity, and neuroplasticity [55], and is associated with a generally negative effect on emotions and cognition [56]. Recent studies also implicated a role for TNF-alpha in neurotransmission and other aspects of neuronal function [57], and interaction with both dopaminergic and serotonergic systems [58]. The TNF-alpha level was found to have a negative correlation with cognitive function in bipolar disorder [59] and was associated with impaired executive functioning in inhibitory control and motor programming among bipolar patients [60]. Furthermore, the level of TNF-alpha was reportedly suggested to be the response predictor of lithium [61]. Our present study showed 12 gray matter volume differences between BP and UD patients negatively correlating with sIL-6R and sTNF-R1 levels. The
12 brain areas covered most findings in previous studies, including hippocampal gray matter volume [48], the inferior temporal poles, left frontopolar gyri, and right subcentral gyrus [51]. In summary, our study results suggest that elevated immune-inflammatory signaling is relevant to the pathophysiology of mood disorders.

In this study, we also found that the BD patients had significantly higher BMI than UD patients. The results were consistent with our previous 10-year cohort study that BP patients have increased risks of metabolic abnormalities in comparison with the UD patients [62]. We further found that BMI significantly correlated with the level of proinflammatory cytokines. Based on the results showing the reduced gray matter volume associated with the level of inflammatory cytokines, it is clinically important to monitor BMI. The previous study showed that patients with metabolic syndrome had significant reductions in mean cortical thickness and volume in both hemispheres compared with controls [60]. Our previous study also found that BD patients with obesity and metabolic diseases are associated with poor clinical outcomes, including more hospitalizations, more severe tardive dyskinesia, poor insight, poor global function, and more impaired executive function [63]. Other studies also found that BD patients with obesity had a longer illness duration, poorer global function, more disabilities, and poorer response to lithium [64], and poor cognitive function [65-68] than non-obese patients did.

There are some limitations to our study. First, our study is a cross-sectional study design and the patients were not drug-free. In addition to the variables adjusted for in the regression model (i.e., age, gender, illness duration, BMI and ITV), psychiatric medication, such as mood stabilizers and atypical antipsychotics, are known to cause metabolic adverse effects, inflammatory cytokines, and brain gray matter changes. Allowing patients to continue their medications was ethically more appropriate and prevented disease relapse; also, it could provide more naturalistic data. In our analysis, similar to our previous reports [30], no significant differences in any of the cytokines were noted among patients taking 
different groups of medications in the BD or UD group, but the effects of medication on cytokines are still difficult to elucidate. A drug-free and prospective study design may be required to confirm our findings. Second, we enrolled a group of patients who were in a mildly ill condition (CGI-S $\leq 3$ ), which included remitted, hypomanic or minor depression states, in the current study. The metabolic, immune, and brain gray matter changes in the acute phase of bipolar disorder and unipolar depression and in different mood states would need further investigation. Third, the inflammatory cytokines can be influenced by body weight and medical comorbidity, and the subjects without bipolar or unipolar disorder may still have high cytokine levels under the circumstances. Therefore, the high cytokine level alone is not a single factor to differentiate mood disorders, and the associated factors should be considered. Finally, there was no healthy control group in the present study. Future studies with a control group are required to validate the results.

\section{Conclusions}

Our results suggested that BD patients had higher BMI and pro-inflammatory cytokines levels than UD patients, especially IL-6 and sTNF-R1, which may contribute to greater gray matter reductions in BD patients in comparison to UD patients. The results support the neuroinflammation pathophysiology mechanism in mood disorder. It is clinically important to monitor BMI, which positively correlated with levels of inflammatory cytokines.

\begin{abstract}
Abbreviations
AFNI: The Analysis of Functional Neurolmages; ANCOVA: Analysis of covariance; BD: Bipolar disorder; BMI: Body mass index; CGI-S: Clinical Global Impression-Severity; CRP: C-reactive protein; DSM-IV-TR: The Diagnostic and Statistical Manual of Mental Disorders, Fourth Edition, Text Revision; ELISA: Enzyme-linked immunosorbent assay; FEW: Family-wise error rate; GM: Gray matter; HDL: High-density lipoprotein; HPA: Hypothalamic-pituitaryadrenal; MetS: Metabolic syndrome; mPFC: Medial prefrontal cortex; sIL2R: Soluble interleukin-2 receptor; sIL-6R: Soluble interleukin-6 receptor; sTNFR1: Soluble tumor necrosis factor receptor type 1; TIV: Total intracranial volume; UD: Unipolar depression
\end{abstract}

\section{Acknowledgements}

The authors wish to acknowledge Emily Ting for English editing.

\section{Financial disclosure}

All authors have no financial relationships relevant to this article to disclose.

\section{Authors' contributions}

YMB and SJT drafted the manuscript. PCT carried out MRI acquisition, data analysis, and interpretation. MHC, JWH, KLH, TPS, WCC, and CTL participated in the design of the study and performed the statistical analysis. YMB conceived of the study and participated in its design and coordination. All authors read and approved the final manuscript.

\section{Funding}

The study was supported by the grant from Taipei Veterans General Hospital (V103E10-001, V104E10-002, V105E10-001-MY2-1, V105A-049,

V105DHA0100104, V107B-010, V107C-181, V108D44-001-MY3-1, V109C-196) and National Science Council (NSC104-2314-B-075-017, MOST 109-2634-F075-001).

\section{Availability of data and materials}

The datasets generated during and/or analyzed during the current study are not publicly available due to the intelligence rights owned by the hospital and the authors but are available from the corresponding author on reasonable request.

\section{Ethics approval and consent to participate}

This study was conducted in accordance with the Declaration of Helsinki and was approved by the Institutional Review Board of Taipei Veterans General Hospital. The study participants agreed on the participation of the study with written informed consent.

\section{Consent for publication}

Not applicable.

\section{Competing interests}

The authors declare that they have no competing interests.

\section{Author details}

${ }^{1}$ Department of Psychiatry, Taipei Veterans General Hospital, No. 201, Shih-Pai Road, Sec. 2, 11217 Taipei, Taiwan. 2Division of Psychiatry, Faculty of Medicine, National Yang-Ming University, Taipei, Taiwan. ${ }^{3}$ Institute of Brain Science, National Yang-Ming University, Taipei, Taiwan. ${ }^{4}$ Department of Medical Research, Taipei Veterans General Hospital, Taipei, Taiwan. ${ }^{5}$ Institute of Philosophy of Mind and Cognition, National Yang-Ming University, Taipei, Taiwan. ${ }^{6}$ Department of Psychiatry, Cheng Hsin General Hospital, Taipei, Taiwan.

Received: 28 October 2019 Accepted: 23 January 2020

Published online: 30 January 2020

\section{References}

1. Krishnadas R, Cavanagh J. Depression: an inflammatory illness? J Neurol Neurosurg Psychiatry. 2012;83:495-502.

2. Bortolato B, Carvalho AF, Soczynska JK, Perini Gl, Mclntyre RS. The involvement of TNF-alpha in cognitive dysfunction associated with major depressive disorder: an opportunity for domain specific treatments. Curr Neuropharmacol. 2015;13:558-76

3. Maes M, Mihaylova I, Kubera M, Ringel K. Activation of cell-mediated immunity in depression: association with inflammation, melancholia, clinical staging and the fatigue and somatic symptom cluster of depression. Prog Neuro-Psychopharmacol Biol Psychiatry. 2012;36:169-75.

4. Moorman AJ, Mozaffarian D, Wilkinson CW, Lawler RL, McDonald GB, Crane BA, Spertus JA, Russo JE, Stempien-Otero AS, Sullivan MD, Levy WC. In patients with heart failure elevated soluble TNF-receptor 1 is associated with higher risk of depression. J Card Fail. 2007;13:738-43.

5. Musselman DL, Miller AH, Porter MR, Manatunga A, Gao F, Penna S, Pearce BD, Landry J, Glover S, McDaniel JS, Nemeroff CB. Higher than normal plasma interleukin-6 concentrations in cancer patients with depression: preliminary findings. Am J Psychiatry. 2001;158:1252-7.

6. Suarez EC, Krishnan RR, Lewis JG. The relation of severity of depressive symptoms to monocyte-associated proinflammatory cytokines and chemokines in apparently healthy men. Psychosom Med. 2003:65:362-8.

7. Sperner-Unterweger B, Kohl C, Fuchs D: Immune changes and neurotransmitters: Possible interactions in depression?. Prog Neuropsychopharmacol Biol Psychiatry. 2014;48:268-76.

8. Jones KA, Thomsen C. The role of the innate immune system in psychiatric disorders. Mol Cell Neurosci. 2013;53:52-62.

9. McNamara RK, Lotrich FE. Elevated immune-inflammatory signaling in mood disorders: a new therapeutic target? Expert Rev Neurother. 2012;12: 1143-61.

10. Rethorst CD, Toups MS, Greer TL, Nakonezny PA, Carmody TJ, Grannemann BD, Huebinger RM, Barber RC, Trivedi MH: Pro-inflammatory cytokines as predictors of antidepressant effects of exercise in major depressive disorder. Mol Psychiatry. 2013;18:1119-24.

11. Capuron L, Ravaud A, Gualde N, Bosmans E, Dantzer R, Maes M, Neveu PJ. Association between immune activation and early depressive symptoms in 
cancer patients treated with interleukin-2-based therapy. Psychoneuroendocrinology. 2001;26:797-808.

12. Su KP. Biological mechanism of antidepressant effect of omega-3 fatty acids: how does fish oil act as a 'mind-body interface'? Neurosignals. 2009;17:144-52

13. Altamura AC, Mundo E, Cattaneo E, Pozzoli S, Dell'osso B, Gennarelli M, Vergani C, Trabattoni D, Arosio B, Clerici M. The MCP-1 gene (SCYA2) and mood disorders: preliminary results of a case-control association study. Neuroimmunomodulation. 2010;17:126-31.

14. Leboyer M, Soreca I, Scott J, Frye M, Henry C, Tamouza R, Kupfer DJ. Can bipolar disorder be viewed as a multi-system inflammatory disease? J Affect Disord. 2012;141:1-10.

15. Stertz L, Magalhaes PV, Kapczinski F. Is bipolar disorder an inflammatory condition? The relevance of microglial activation. Curr Opin Psychiatry. 2013; 26:19-26.

16. Jones KA, Thomsen $C$. The role of the innate immune system in psychiatric disorders. Mol Cell Neurosci. 2013;53:52-62.

17. Zunszain PA, Hepgul N, Pariante CM. Inflammation and Depression. Curr Top Behav Neurosci. 2013;14:135-51.

18. Bora E, Fornito A, Pantelis C, Yucel M. Gray matter abnormalities in major depressive disorder: a meta-analysis of voxel based morphometry studies. J Affect Disord. 2012;138:9-18.

19. Bora E, Fornito A, Yucel M, Pantelis C. Voxelwise meta-analysis of gray matter abnormalities in bipolar disorder. Biol Psychiatry. 2010;67:1097-105.

20. Ganzola R, Duchesne S. Voxel-based morphometry meta-analysis of gray and white matter finds significant areas of differences in bipolar patients from healthy controls. Bipolar Disord. 2017;19:74-83.

21. Kempton MJ, Salvador Z, Munafo MR, Geddes JR, Simmons A, Frangou S, Williams SC. Structural neuroimaging studies in major depressive disorder. Meta-analysis and comparison with bipolar disorder. Arch Gen Psychiatry. 2011;68:675-90

22. Fuhr K, Hautzinger M, Meyer TD. Implicit motives and cognitive variables: specific links to vulnerability for unipolar or bipolar disorder. Psychiatry Res. 2014;215:61-8

23. Sasayama D, Hori H, Teraishi T, Hattori K, Ota M, Matsuo J, Kawamoto Y, Kinoshita Y, Hashikura M, Amano N, et al. More severe impairment of manual dexterity in bipolar disorder compared to unipolar major depression. J Affect Disord. 2012:136:1047-52.

24. Hermens DF, Naismith SL, Redoblado Hodge MA, Scott EM, Hickie IB. Impaired verbal memory in young adults with unipolar and bipolar depression. Early Interv Psychiatry. 2010;4:227-33.

25. Smith DJ, Muir WJ, Blackwood DH. Neurocognitive impairment in euthymic young adults with bipolar spectrum disorder and recurrent major depressive disorder. Bipolar Disord. 2006;8:40-6.

26. Beyer JL. Volumetric brain imaging studies in the elderly with mood disorders. Curr Psychiatry Rep. 2006;8:18-24.

27. Cardoso de Almeida JR, Phillips ML. Distinguishing between unipolar depression and bipolar depression: current and future clinical and neuroimaging perspectives. Biol Psychiatry. 2013;73:111-8.

28. Strakowski SM, Adler CM, DelBello MP. Volumetric MRI studies of mood disorders: do they distinguish unipolar and bipolar disorder? Bipolar Disord. 2002:4:80-8

29. Beyer JL, Krishnan KR. Volumetric brain imaging findings in mood disorders. Bipolar Disord. 2002;4:89-104.

30. Cai Y, Liu J, Zhang L, Liao M, Zhang Y, Wang L, Peng H, He Z, Li Z, Li W, Lu S, Ding Y, Li L. Grey matter volume abnormalities in patients with bipolar I depressive disorder and unipolar depressive disorder: a voxel-based morphometry study. Neurosci Bull. 2015;31(1):4-12.

31. Redlich R, Almeida JJ, Grotegerd D, Opel N, Kugel H, Heindel W, Arolt $V$, Phillips ML, Dannlowski U. Brain morphometric biomarkers distinguishing unipolar and bipolar depression. A voxel-based morphometry-pattern classification approach. JAMA Psychiatry. 2014; 71(11):1222-30.

32. Bai YM, Su TP, Li CT, Tsai SJ, Chen MH, Tu PC, Chiou WF. Comparison of proinflammatory cytokines among patients with bipolar disorder and unipolar depression and normal controls. Bipolar Disord. 2015;17:269-77.

33. Tu PC, Li CT, Lin WC, Chen MH, Su TP, Bai YM. Structural and functional correlates of serum soluble IL-6 receptor level in patients with bipolar disorder. J Affect Disord. 2017;219:172-7.

34. Li CT, Chou KH, Su TP, Huang CC, Chen MH, Bai YM, Lin CP. Gray matter abnormalities in schizophrenia patients with tardive dyskinesia: a magnetic resonance imaging voxel-based morphometry study. PLoS One. 2013;33(3): 313-8.

35. Bai YM, Chiou WF, Su TP, Li CT, Chen MH. Pro-inflammatory cytokine associated with somatic and pain symptoms in depression. J Affect Disord. 2014;155:28-34.

36. Bai YM, Su TP, Tsai SJ, Wen-Fei C, Li CT, Pei-Chi T, Mu-Hong C. Comparison of inflammatory cytokine levels among type I/type II and manic/ hypomanic/euthymic/depressive states of bipolar disorder. J Affect Disord. 2014;166:187-92.

37. Wise T, Radua J, Via E, Cardoner N, Abe O, Adams TM, Amico F, Cheng Y, Cole $\mathrm{JH}$, de Azevedo Marques Perico C. Common and distinct patterns of greymatter volume alteration in major depression and bipolar disorder: evidence from voxel-based meta-analysis. Mol Psychiatry. 2017;22(10):1455-63.

38. Ocklenburg S, Friedrich P, Güntürkün O, Genç E. Voxel-wise grey matter asymmetry analysis in left- and right-handers. Neurosci Lett. 2016;633:210-4

39. Munkholm K, Braüner JV, Kessing LV, Vinberg M. Cytokines in bipolar disorder vs. healthy control subjects: a systematic review and meta-analysis. J Psychiatr Res. 2013;47:1119-33.

40. Modabbernia A, Taslimi S, Brietzke E, Ashrafi M. Cytokine alterations in bipolar disorder: a meta-analysis of 30 studies. Biol Psychiatry. 2013;74: $15-25$.

41. Tsai SY, Lee $\mathrm{CH}$, Huang SH, Chung KH, Chen PH. Soluble interleukin-6 receptor level reflecting the illness activity in bipolar disorder. Aust N Z J Psychiatry. 2014;48:382-3.

42. Hayes JF, Khandaker GM, Anderson J, Mackay D, Zammit S, Lewis G, Smith DJ, Osborn DP. Childhood interleukin-6, C-reactive protein and atopic disorders as risk factors for hypomanic symptoms in young adulthood: a longitudinal birth cohort study. Psychol Med. 2017;47:23-33.

43. Anticevic A, Brumbaugh MS, Winkler AM, Lombardo LE, Barrett J, Corlett PR, Kober H, Gruber J, Repovs G, Cole MW, et al. Global prefrontal and frontoamygdala dysconnectivity in bipolar I disorder with psychosis history. Biol Psychiatry. 2013;73:565-73.

44. Goldsmith DR, Haroon E, Woolwine BJ, Jung MY, Wommack EC, Harvey PD, Treadway MT, Felger JC, Miller AH. Inflammatory markers are associated with decreased psychomotor speed in patients with major depressive disorder. Brain Behav Immun. 2016;56:281-8.

45. Harrison NA, Brydon L, Walker C, Gray MA, Steptoe A, Critchley HD. Inflammation causes mood changes through alterations in subgenual cingulate activity and mesolimbic connectivity. Biol Psychiatry. 2009;66: 407-14.

46. Satizabal CL, Zhu YC, Mazoyer B, Dufouil C, Tzourio C. Circulating IL-6 and CRP are associated with MRI findings in the elderly: the 3C-Dijon study. Neurology. 2012;78:720-7.

47. Jefferson AL, Massaro JM, Wolf PA, Seshadri S, Au R, Vasan RS, Larson MG, Meigs JB, Keaney JF Jr, Lipinska I, et al. Inflammatory biomarkers are associated with total brain volume: the Framingham Heart Study. Neurology. 2007:68:1032-8.

48. Marsland AL, Gianaros PJ, Abramowitch SM, Manuck SB, Hariri AR. Interleukin-6 covaries inversely with hippocampal grey matter volume in middle-aged adults. Biol Psychiatry. 2008;64:484-90.

49. Lindlau A, Widmann CN, Putensen C, Jessen F, Semmler A, Heneka MT Predictors of hippocampal atrophy in critically ill patients. Eur J Neurol. 2015:22:410-5.

50. Baune BT, Ponath $\mathrm{G}$, Rothermundt M, Roesler A, Berger K. Association between cytokines and cerebral MRI changes in the aging brain. J Geriatr Psychiatry Neurol. 2009;22:23-34.

51. McCarrey AC, Pacheco J, Carlson OD, Egan JM, Thambisetty M, An Y, Ferrucci L, Resnick SM. Interleukin-6 is linked to longitudinal rates of cortical thinning in aging. Transl Neurosci. 2014;5:1-7.

52. Hope S, Ueland T, Steen NE, Dieset I, Lorentzen S, Berg AO, Agartz I, Aukrust $P$, Andreassen OA. Interleukin 1 receptor antagonist and soluble tumor necrosis factor receptor 1 are associated with general severity and psychotic symptoms in schizophrenia and bipolar disorder. Schizophr Res. 2013;145: 36-42.

53. Park KM, Bowers WJ. Tumor necrosis factor-alpha mediated signaling in neuronal homeostasis and dysfunction. Cell Signal. 2010;22:977-83.

54. Verma S, Nakaoke R, Dohgu S, Banks WA. Release of cytokines by brain endothelial cells: a polarized response to lipopolysaccharide. Brain Behav Immun. 2006;20:449-55.

55. Iosif RE, Ekdahl CT, Ahlenius H, Pronk CJ, Bonde S, Kokaia Z, Jacobsen SE, Lindvall O. Tumor necrosis factor receptor 1 is a negative regulator of 
progenitor proliferation in adult hippocampal neurogenesis. J Neurosci. 2006;26:9703-12.

56. Reichenberg A, Yirmiya R, Schuld A, Kraus T, Haack M, Morag A, Pollmacher T. Cytokine-associated emotional and cognitive disturbances in humans. Arch Gen Psychiatry. 2001;58:445-52.

57. Figiel I. Pro-inflammatory cytokine TNF-alpha as a neuroprotective agent in the brain. Acta Neurobiol Exp (Wars). 2008;68:526-34.

58. Muller N, Ackenheil M. Psychoneuroimmunology and the cytokine action in the CNS: implications for psychiatric disorders. Prog NeuroPsychopharmacol Biol Psychiatry. 1998;22:1-33.

59. Doganavsargil-Baysal O, Cinemre B, Aksoy UM, Akbas $\mathrm{H}$, Metin $\mathrm{O}$, Fettahoglu C, Gokmen Z, Davran F. Levels of TNF-alpha, soluble TNF receptors (sTNFR1, sTNFR2), and cognition in bipolar disorder. Hum Psychopharmacol. 2013;28:160-7.

60. Barbosa IG, Rocha NP, Huguet RB, Ferreira RA, Salgado JV, Carvalho LA, Pariante CM, Teixeira AL. Executive dysfunction in euthymic bipolar disorder patients and its association with plasma biomarkers. J Affect Disord. 2012; 137:151-5.

61. Guloksuz S, Altinbas K, Aktas Cetin E, Kenis G, Bilgic Gazioglu S, Deniz G, Oral ET, van Os J. Evidence for an association between tumor necrosis factor-alpha levels and lithium response. J Affect Disord. 2012;143:148-52.

62. Bai YM, Su TP, Chen MH, Chen TJ, Chang WH. Risk of developing diabetes mellitus and hyperlipidemia among patients with bipolar disorder, major depressive disorder, and schizophrenia: a 10-year nationwide populationbased prospective cohort study. J Affect Disord. 2013;150:57-62.

63. Trevino S, Aguilar-Alonso P, Flores Hernandez JA, Brambila E, Guevara J, Flores G, Lopez-Lopez G, Munoz-Arenas G, Morales-Medina JC, Toxqui V, et al. A high calorie diet causes memory loss, metabolic syndrome and oxidative stress into hippocampus and temporal cortex of rats. Synapse. 2015;69:421-33.

64. Song SW, Chung JH, Rho JS, Lee YA, Lim HK, Kang SG, Kim HN, Kim JE, Kim SH. Regional cortical thickness and subcortical volume changes in patients with metabolic syndrome. Brain Imaging Behav. 2015;9:588-96.

65. Bai YM, Li CT, Tsai SJ, Tu PC, Chen MH, Su TP. Metabolic syndrome and adverse clinical outcomes in patients with bipolar disorder. BMC Psychiatry. 2016;16:448.

66. Calkin C, van de Velde C, Ruzickova M, Slaney C, Garnham J, Hajek T, O'Donovan C, Alda M. Can body mass index help predict outcome in patients with bipolar disorder? Bipolar Disord. 2009;11:650-6.

67. Galvez JF, Bauer IE, Sanches M, Wu HE, Hamilton JE, Mwangi B, Kapczinski FP, Zunta-Soares G, Soares JC. Shared clinical associations between obesity and impulsivity in rapid cycling bipolar disorder: a systematic review. J Affect Disord. 2014;168:306-13.

68. Yim CY, Soczynska JK, Kennedy SH, Woldeyohannes HO, Brietzke E, McIntyre RS. The effect of overweight/obesity on cognitive function in euthymic individuals with bipolar disorder. Eur Psychiatry. 2012;27:223-8.

\section{Publisher's Note}

Springer Nature remains neutral with regard to jurisdictional claims in published maps and institutional affiliations.

\section{Ready to submit your research? Choose BMC and benefit from}

- fast, convenient online submission

- thorough peer review by experienced researchers in your field

- rapid publication on acceptance

- support for research data, including large and complex data types

- gold Open Access which fosters wider collaboration and increased citations

- maximum visibility for your research: over $100 \mathrm{M}$ website views per year

At $\mathrm{BMC}$, research is always in progress.

Learn more biomedcentral.com/submissions 